\title{
Universiteit
}

Leiden

The Netherlands

\section{Patient's need for choice and information across the interface between primary and secondary care: A survey}

Berendsen, A.J.; Jong, G.M. de; Schuling, J.; Bosveld, H.E.P.; Waal, M.W.M. de; Mitchell, G.K.; ... ; Meyboom-de Jong, B.

\section{Citation}

Berendsen, A. J., Jong, G. M. de, Schuling, J., Bosveld, H. E. P., Waal, M. W. M. de, Mitchell, G. K., ... Meyboom-de Jong, B. (2010). Patient's need for choice and information across the interface between primary and secondary care: A survey. Patient Education And

Counseling, 79(1), 100-105. Retrieved from https://hdl.handle.net/1887/117599

Version: $\quad$ Not Applicable (or Unknown)

License: $\quad$ Leiden University Non-exclusive license

Downloaded from: https://hdl.handle.net/1887/117599

Note: To cite this publication please use the final published version (if applicable). 


\title{
Patient's need for choice and information across the interface between primary and secondary care: A survey
}

\author{
Annette J. Berendsen ${ }^{\mathrm{a}, *}$, G. Majella de Jong ${ }^{\mathrm{a}}$, Jan Schuling ${ }^{\mathrm{a}}$, Henk E.P. Bosveld ${ }^{\mathrm{a}}$, Margot W.M. de Waal ${ }^{\mathrm{b}}$, \\ Geoffrey K. Mitchell ${ }^{c}$, Klaas van der Meer ${ }^{a}$, Betty Meyboom-de Jong ${ }^{a}$
}

${ }^{a}$ Department of General Practice, University Medical Centre Groningen, University of Groningen, The Netherlands

${ }^{\mathrm{b}}$ Department of Public Health and Primary Care, Leiden University Medical Centre, The Netherlands

${ }^{\mathrm{c}}$ Discipline of General Practice, Mayne Medical School, University of Queensland, Australia

\section{A R T I C L E I N F O}

\section{Article history:}

Received 26 February 2009

Received in revised form 20 July 2009

Accepted 22 July 2009

\section{Keywords:}

Patients' choice

Patients' perceptions

Information

Interface between primary and secondary care

\begin{abstract}
A B S T R A C T
Objective: Hospitals in the Netherlands have recently made certain performance data public, allowing patients to choose the location of their care. The objective of this study is to assess (a) patient preferences and experiences concerning the transition between primary and secondary health care, (b) patients' needs for choice and information and how these are influenced by personal and morbidity factors. Methods: Two different types of questionnaires were used. The first questionnaire concerns the importance that patients attach to the care provided. The second questionnaire concerns the actual experiences of the patient with the care provided.

For the selection of patients, we used the databases of the registration networks of the Departments of General Practice of the Universities of Groningen and Leiden. The questionnaires were returned by 513 patients (Importance 69\%) and 1404 patients (Experience 65\%).

Results: Many patients prefer the GP advising them regarding which hospital or specialist they should be referred to: a quarter of the patients preferred that the GP decided for them. Patients with a curable condition and patients aged between 25 and 65, highly educated and with stable personal characteristics as measured by a purposive scale, more often wished to use information from internet or newspapers to make a decision.

The amount of information that was needed on illness or treatment varied greatly. Young people, older people, and those with less stable personal characteristics more often desired only practical information.

Conclusions: In spite of making performance data of different health care institutions public, only a limited number of patients want to use this information on a limited number of health problems. Practice implications: Care providers should take differences into account concerning patients' need for information on their illness.
\end{abstract}

(c) 2009 Elsevier Ireland Ltd. All rights reserved.

\section{Introduction}

Starting January 1st 2006, a new health care system was introduced in the Netherlands with the expectation that this should lead to increased market forces and competition in health care $[1,2]$. The Netherlands government funded a website that provides information on outcomes of health care institutions, health insurance providers, and information on specific illnesses

\footnotetext{
* Corresponding author at: Department of General Practice, University Medical Centre Groningen, University of Groningen, Ant. Deusinglaan 1, 9713 AV Groningen, The Netherlands. Tel.: +31 50 3632975; fax: +31 503637445 .

E-mail address: a.j.berendsen@med.umcg.nl (A.J. Berendsen).
}

(www.KiesBeter.nl), in order to encourage patients to become critical consumers of health care services.

Patients in the Netherlands are free to choose their hospital of preference for treatment. They usually need a GP's referral for access to secondary care: the GP functions as gatekeeper to specialized health care.

Discussion has arisen between advocates and opponents of this development. Some claim this freedom is a privilege, others say the patient is burdened with the freedom of choice. However, it is not known whether patients base their choices on their physicians' attitudes, certain service aspects (meals, etc.) or on real quality of care.

Both in the United States and in Great Britain, experience has already been gained in the publishing of choice-supporting information on health care. The provision of this information 
has not led to changes in the choice making of either patients, referring physicians or care buyers (insurers) [3-6]. It did, however, lead to improvements in outcomes of health care institutions, possibly because they fear a loss of reputation or market share $[7,8]$.

In Great Britain, surveys have consistently shown that patients want to make choices. The 2005 British Social Attitudes survey found $65 \%$ of patients wanted choice of treatment, $63 \%$ wanted a choice of hospital and 53\% welcomed a choice of appointment time [9]. The question is what these patients base their choices on, if not choice-supporting information.

In our qualitative research on patients' experience across the interface between primary and secondary care, the need to make one's own health care choices did not spontaneously arise during the focus group sessions [10]. When asked directly, many patients said they found it either too difficult or felt too ill to make their own choices. On the other hand, the need to receive personalized information on illnesses and treatment options was expressed clearly.

To be able to enact policy based on patient's choice, one needs to know who the patient is and how and what this patient chooses under different circumstances. What do health care consumers want? What are their expectations and what kind of support do they need? What does this mean in practice? In order to be able to give recommendations for change, it is important to compare patients' wishes to actual experiences.

Based on this consideration, we decided the following research questions.

What are patient preferences and experiences concerning the transition between primary and secondary health care?

What are patients' needs for choice and information and how are these influenced by personal and morbidity characteristics?

In addition, we planned to test the following hypotheses arising from our qualitative research [10]:

- The GP plays an important advisory role during the referral. Patients do not always wish to choose the type of care themselves, nor do they always feel capable of doing so.

- The amount of information desired by individual patients varies considerably. Some patients report that too much information increases their anxiety. However, the internet is also used by the elderly, though sometimes with help from others.

- Patients wish to receive more information on the timing of discharge and on what they can expect after discharge with respect to symptoms and continuing complaints. This was most evident in patients suffering from a curable condition.

\section{Methods}

A cross-sectional study was conducted using questionnaires. The study design was reviewed by the Medical Ethics Committee of the University Medical Centre Groningen. They determined that ethical approval was not required.

\subsection{Questionnaire development}

In order to measure both the importance of the care provided and patients' actual experiences with this health care, a new 'family' of questionnaires was created in the Netherlands, based on two existing 'families' of questionnaires (QUOTE and CAHPS ${ }^{\circledR}$ ) $[11,12]$. This new 'family' is named Consumers Quality Index (CQI). It consists of two questionnaires.

The first questionnaire, CQI-Importance, concerns the importance that patients attach to the care provided. The items were formulated as follows: 'I want to be free in my choice of hospital. I find this .... The answer categories are ordered ordinally (not important, slightly important, important, extremely important), unless multiple response answers are appropriate to the question.

The second questionnaire, CQI-Experience, concerns the actual experiences of the patient with the care provided. These items are formulated as follows: 'I chose the hospital myself'. The answer categories are generally dichotomous (yes/no).

The items are formulated based on themes from our earlier qualitative, explorative research among patients [10]. Thirteen test questionnaires were completed by patients from varying educational backgrounds. This was done to check the applicability of the questionnaire in terms of comprehension, formulation, length of time, and to subsequently improve these if necessary.

Both questionnaires contain questions regarding general characteristics of respondents, such as age and gender and questions on personal characteristics which were derived from the focus group research (assertiveness, mastery, anxiety, depression and self-reported health). These personal characteristics are ascertained using an ordinal 4-point scale (never/sometimes/ usually/always) or a 5-point scale (self-reported health: excellent to bad).

\subsection{Patients}

We used the databases of the registration networks of the departments of General Practice of the Universities of Groningen and Leiden to select patients. These two databases contain data from three solo and six group practices in the North and West of the Netherlands (about 60,000 patients).

Patients who were over 18 years of age and who had been referred to a medical specialist in the last 2 years (excluding referrals to paediatricians and psychiatrists) were identified. We decided on a 2-year time period as our focus group meetings showed that recall within this time span was vivid. The surveys sought opinions about the whole referral process of the most recent referral and all contacts resulting from that referral. Of the patients 14,468 met the inclusion criteria. The selection of patients was stratified by the patient's referring GP and age.

The questionnaires were sent to two random samples of respectively 744 (CQI-Importance) and 2159 (CQI-Experience) patients from the selected population. The sample required to test importance is smaller, because research with the CQI questionnaires has shown that patients hardly differ in the importance they attach to provided health care, both in field studies as well as longitudinal studies. The standard deviation is small, so a smaller sample size is required to identify differences between groups. A reminder was sent to the non-respondents, and later on another questionnaire as well as a reminder was sent [13]. Eventually the responses added up to 513 useable Importance questionnaires and 1404 useable Experience questionnaires returned (respectively 69 and 65\%). Through the databases, age and gender of the nonrespondents was known. Patients were asked to identify the medical conditions they suffered. It is our opinion that the care needed for treatment of these conditions differs to such an extent, that the preferences and experiences patients have with treatment should be analyzed per illness category as well.

The study was conducted between the months of April and September of 2007.

\subsection{Questionnaire}

The influence of personal characteristics was analyzed using separate items such as age and gender, and by devising subscales based on personal characteristics. A factor analysis was conducted on the items concerning these personal characteristics 
(assertiveness, mastery, anxiety, depression and self-reported health) in order to devise subscales. Based on the screenplot, the number of factors for factor analysis was determined and subsequently rotated according to the varimax criterion. The explained variance of the factors was calculated. The internal consistency was verified by correlating the item scores with the total scores of every scale, minus the score of the item concerned (item-rest correlation). Cronbach's alpha coefficients were determined $[14,15]$.

Two researchers independently categorized the illnesses that were reported by the patients into the following categories: chronic illness (e.g. diabetes, COPD, chronic arthritis), curable condition (e.g. hip operation, plastic surgery), medically unexplained physical symptoms (MUPS), cancer and other.

The data were analyzed using the SPSS statistical package. Analyses used parametric and non-parametric tests as appropriate. When comparing two categories, the Chi-square or MannWhitney test was used, for more than two categories the Kruskal-Wallis test or the ANOVA was used. A $p$-value $<0.05$ was considered significant.

\section{Results}

\subsection{Questionnaire development}

For questions in both questionnaires containing questions about personal characteristics (assertiveness, mastery, anxiety, depression and self-reported health), two factors produced the best results, explaining 48\% (Importance) and 51\% (Experience) of the total variance. Two factors were rotated (eigenvalue $>1$ ). This resulted in two scales relating to patient characteristics for both questionnaires, which we labelled Stable (Cronbach's alpha Importance: 0.73, Experience: 0.73) and Stressed (Cronbach's alpha Importance: 0.79, Experience: 0.83) (Table 1).

The first results show that adult patients (25-65 years of age) who scored high on the Stable scale (scale score $\geq 15$ ) and who are fairly highly educated (completed at least GCSE-basic high school qualification, 73\%), made up a different group with regards to the making of choices, the use of choice-supporting information and the need for information. For this reason, we formed a subgroup of these patients (Stahiad: stable - higher educated - adult). In both questionnaires, respectively 26\% (Importance) and 28\% (Experience) of respondents came from this subgroup.

\subsection{Respondent characteristics}

The characteristics of the 513 and 1404 respondents are listed in Table 2 . The male/female ratio is $40 / 60 \%$. Age and gender of the 712 non-respondents and the average level of education in the Netherlands are also listed in Table 3. There are more older people among the respondents. The distribution of the education level of respondents is comparable to the general distribution in the Netherlands. The older respondents $(65+)$ are largely from a lower educational background (Importance list: 52\%; Experience list: 39\%).

\subsection{The choice of care provider}

The results are listed in Table 3 and discussed below.

\subsubsection{Role of the GP}

Most patients ( $81 \%$ ) thought it important that the GP gave them advice on which hospital or specialist to go to when they referred the patient. For a smaller number of patients (67\%), the GP indeed gave this advice.

A quarter (25\%) of the patients found it important that the GP decided for them which hospital or specialist to attend; for a larger number of patients (33\%) the GP indeed made that decision. This was significantly more often the case for emergency patients (45\%) than for other patients $(p=0.001)$.

Older people more often than young people $(65+: 38 \% ;<65$ : $20 \%, p=0.001)$ and lower educated people (42\%) more often than higher educated people ( $19 \% ; p<0.0005)$ wanted the GP to make a decision regarding hospital or specialist. In practice, the GP indeed did this for lower educated more often $(43 \% ; p<0.0005)$. Patients scoring lower on the Stable scale also wished the GP to make a decision more often. This relation is significant and linear, for Importance as well as Experience (respectively $p=0.003$ and $p=0.002$ ANOVA). Patients scoring positively on the Stressed scale showed no difference. There was also no difference found between men and women. Half of the patients suffering from MUPS wished the GP to make a decision. Stahiad patients wanted the GP to make a decision significantly less often (Stahiad 16\%, non-Stahiad 28\%; $p=0.008$ ) and in practice, this indeed occurred less often $(p<0.0005)$ compared to the other patients.

\subsubsection{Making own choice}

Patients thought it important that they chose a hospital themselves (70\%) and to a lesser degree a specialist (56\%). In

Table 1

The Stressed and Stable scales.

\begin{tabular}{|c|c|c|c|}
\hline Scales (Importance $n=513$, Experience $n=1404$ ) & $\begin{array}{l}\text { Usually + always } \\
\text { (Importance/ } \\
\text { Experience) (\%) }\end{array}$ & $\begin{array}{l}\text { Item-rest correlation } \\
\text { (Importance/Experience) }\end{array}$ & $\begin{array}{l}\text { Cronbach's Alpha } \\
\text { (Importance/Experience) }\end{array}$ \\
\hline Stressed & & & $0.79 / 0.83$ \\
\hline I feel nervous, anxious or stressed in every day life. & $4 / 5$ & $0.57 / 0.64$ & \\
\hline When I am ill, I feel nervous, anxious or stressed. & $14 / 11$ & $0.45 / 0.54$ & \\
\hline I feel helpless in dealing with life's problems. & $4 / 3$ & $0.54 / 0.59$ & \\
\hline How would you rate your health in general? (low \%) & $21 / 20$ & $0.44 / 0.52$ & \\
\hline How would you rate your mental/psychological health in general? (low \%) & $10 / 9$ & $0.61 / 0.66$ & \\
\hline $\begin{array}{l}\text { Have you suffered from gloomy, depressive feelings or feelings of helplessness } \\
\text { during the last month? }\end{array}$ & $5 / 3$ & $0.60 / 0.65$ & \\
\hline Have you taken small interest or pleasure in things during the last month? & $7 / 8$ & $0.44 / 0.50$ & \\
\hline Stable & & & $0.73 / 0.73$ \\
\hline I am assertive in every day life. & $92 / 94$ & $0.42 / 0.46$ & \\
\hline When I am ill, I am assertive. & $82 / 89$ & $0.49 / 0.46$ & \\
\hline When I am ill, I am capable of participating in decisions regarding treatment options. & $67 / 72$ & $0.51 / 0.51$ & \\
\hline I am capable of changing important things in my life. & $64 / 72$ & $0.48 / 0.49$ & \\
\hline When I am ill, I am capable of exerting influence on the medical choices being made. & $50 / 60$ & $0.54 / 0.55$ & \\
\hline
\end{tabular}

The numbers for Importance and Experience are given in the same column.

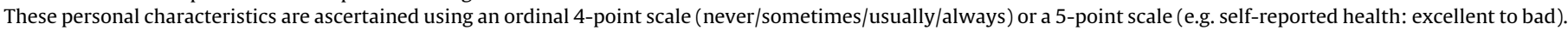


Table 2

Characteristics of respondents.

\begin{tabular}{|c|c|c|c|c|}
\hline & $\begin{array}{l}\text { Respondents } \\
\text { Importance (\%), } n=513\end{array}$ & $\begin{array}{l}\text { Non-respondents } \\
\text { Importance (\%), } n=225\end{array}$ & $\begin{array}{l}\text { Respondents } \\
\text { Experience (\%), } n=1404\end{array}$ & $\begin{array}{l}\text { Non-respondents } \\
\text { Experience (\%), } n=712\end{array}$ \\
\hline \multicolumn{5}{|l|}{ Age } \\
\hline $18-34$ years & 11.5 & $29(p<0.0005)$ & 13 & $31(p<0.0005)$ \\
\hline $35-64$ years & 60.5 & $58(p=0.63)$ & 58 & $55(p=0.20)$ \\
\hline 65 and older & 28 & $13(p<0.0005)$ & 29 & $14(p<0.0005)$ \\
\hline Female & 62 & $56(p=0.15)$ & 60 & $55(p=0.31)$ \\
\hline \multicolumn{5}{|l|}{ Education } \\
\hline Primary school/GCSE (lower educated) & 27 & & 27 & $29(p=0.36)^{\mathrm{a}}$ \\
\hline GCSE & 20 & & 19 & $43(p=0.21)^{\mathrm{a}}$ \\
\hline A-levels & 24 & & 27 & \\
\hline College/university & 29 & & 27 & $28(p=0.64)^{a}$ \\
\hline \multicolumn{5}{|l|}{ Type of illness } \\
\hline Chronic illness & 20 & & 18 & \\
\hline Curable condition & 29 & & 36 & \\
\hline MUPS $^{\mathrm{b}}$ & 1 & & 2 & \\
\hline Cancer & 4 & & 3 & \\
\hline Other & 46 & & 41 & \\
\hline Emergency & 12 & & 12 & \\
\hline
\end{tabular}

a National (\%) Statistics Netherlands (CBS).

b Medically unexplained physical symptoms.

practice, a smaller number of patients chose the hospital itself (61\%) and a specialist (30\%).

Ninety-one percent of respondents wanted to choose a hospital because of proximity of the hospital or personal or relatives' and friends' experiences (three-dimensional cross tab of multiresponse question). For those who actually made the choice themselves ( $n=789$ ), this percentage was $97 \%$.

Patients aged 75 and older more often wanted to choose a hospital nearby ( $71 \% ; p=0.025)$. In practice this mainly concerned patients suffering from cancer (79\%; $p=0.03$ Chi-square).

For educational level $(p=0.53)$, chronic illnesses $(p=0.06)$ and the scales Stable or Stressed, no significant difference was found regarding the choice for a hospital nearby.

A small number of patients wanted to choose a hospital or specialist based on information from a newspaper, the internet or a health insurance company (waiting list mediation). For patients from the Experience list who made their own choice $(n=789)$, these sources of information were less influential (2.6\%). Patients with a curable condition (10\%; $p=0.04$ Chi-square) and Stahiad patients ( $14 \% ; p<0.0005$ Chi-square) wished to use information from newspapers or the internet in making a decision more often.

Table 3

Patient's choice.

\begin{tabular}{lll}
\hline & $\begin{array}{l}\text { Importance } \\
n=513, \text { important } \\
+ \text { extremely } \\
\text { important (\%) }\end{array}$ & $\begin{array}{l}\text { Experience } \\
n=1404, \\
\text { yes (\%) }\end{array}$ \\
& 81 & 67 \\
\hline Advice from GP on hospital/specialist & 25 & 33 \\
GP decides on hospital/specialist & 70 & 61 \\
Own choice of hospital & 56 & 30 \\
Own choice of specialist & & $n=789$ \\
What is important in the choice of & & 58 \\
$\quad$ a specialist/hospital & 52 & 52 \\
The hospital is nearby & 58 & 17 \\
Personal experience & 24 & 3 \\
$\quad$ Experience of relatives/friends & 6 & 2 \\
Information from newspaper/internet & 10 & \\
$\quad$ Advice from health insurer & & 24 \\
$\quad$ (waiting list mediation) & 89 & 10 \\
Free to choose a different specialist & & 66 \\
$\quad$ Not free to change & & \\
$\quad$ NA I did not wish to change & &
\end{tabular}

Many patients (89\%) stated it was important to be able to change specialists if they want to. In practice, $34 \%$ wished to change. In $24 \%$ of cases, they felt free to do so, in $10 \%$ of cases they did not.

\subsection{Information on illness or treatment}

The results are listed in Table 4 and discussed below.

\subsubsection{Amount of information}

Thirteen percent of patients only desired practical information (e.g. what shoes to wear) regarding their illness, while $47 \%$ required further background information and $40 \%$ wanted to know everything there was to know concerning their condition.

Patients aged from 18 to 24 years, and patients over 65 years of age had a greater desire for only practical information (18-24: $27 \%$, $p=0.04$ and $65+: 20 \%, p=0.003)$. The amount of wanted information increased linearly with the score of the Stable scale ( $p=0.001$ ANOVA): as people scored more stable, they also wanted more information. No difference was found on the Stressed scale.

\subsubsection{Source of information on illness or treatment}

Most patients (88\%) wished to receive information through the GP while a smaller majority (59\%) actually received information this way. Sixty-three percent of patients expressed a desire to receive information from the specialist, while $56 \%$ of respondents received information this way (56\%).

Almost a third of the patients (29\%) wished to receive information through the pharmacist and a tenth (11\%) of the patients actually received information this way. Of the chronically ill, significantly more patients (36\%) wished to receive information through the pharmacist than those who actually received information from them $(21 \% ; p=0.02)$.

About a third of the patients (31\%) wanted to get the information through the internet, and a similar proportion used the internet for information (30\%). Older people wished to use the internet less (possibly with the help of others) and they indeed used it less $(65+: 11 \% ; p<0.0005)$. The same holds for lower educated patients $(p<0.0005)$. Of the people who did not finish their GCSEs, about 10\% used the internet for information; of the people who finished only primary school about 3\% used the internet for information. 
Table 4

Information on illness/treatment.

\begin{tabular}{|c|c|c|}
\hline & $\begin{array}{l}\text { Importance } \\
n=513 \text {, } \\
\text { important + } \\
\text { extremely } \\
\text { important (\%) }\end{array}$ & $\begin{array}{l}\text { Experience } \\
n=1404 \\
\text { yes }(\%)\end{array}$ \\
\hline \multicolumn{3}{|l|}{ On my illness/treatment, I wish... } \\
\hline Only practical information & 13 & 15 \\
\hline Practical and background information & 47 & 46 \\
\hline To know every smallest detail concerned & 40 & 39 \\
\hline \multicolumn{3}{|l|}{ To receive information through... } \\
\hline Pharmacist & 29 & 11 \\
\hline Patient information leaflet (medicine) & 23 & 14 \\
\hline Leaflet & 31 & 24 \\
\hline GP & 88 & 59 \\
\hline Internet (poss. with help) & 31 & 30 \\
\hline Patient organization & 11 & 3 \\
\hline Specialist(s) & 63 & 56 \\
\hline Nurse & 17 & 15 \\
\hline View own medical file & 85 & 18 \\
\hline Did not ask/no need & & 76 \\
\hline \multicolumn{3}{|l|}{$\begin{array}{l}\text { Were you, after being referred by the GP, } \\
\text { treated by more than one specialist? }\end{array}$} \\
\hline Yes & $(177=) 36$ & $(430=) 31$ \\
\hline \multirow[t]{2}{*}{ Specialists keep each other well-informed } & $n=177$ & $n=430$ \\
\hline & 100 & 55 \\
\hline More or less & & 28 \\
\hline To receive no contradictory information/ & $n=177$ & $n=430$ \\
\hline Did receive contradictory information & 98 & 19 \\
\hline \multirow{2}{*}{$\begin{array}{l}\text { Sufficient information (in person or } \\
\text { through leaflets) at discharge } \\
\text { from the hospital }\end{array}$} & & $n=505$ \\
\hline & 97 & 84 \\
\hline \multicolumn{3}{|c|}{ Contact with GP after discharge from the hospital } \\
\hline No contact/not necessary & 2 & 40 \\
\hline Make/made contact oneself & 23 & 30 \\
\hline GP make/made contact & 75 & 30 \\
\hline
\end{tabular}

Patients who desired only practical information, used leaflets significantly less often as a source of information (Experience list $15 \% ; p=0.005)$. The same goes for the internet $(9 \%, p<0.0005)$.

\subsubsection{Information at the hospital}

Most patients (85\%) found it important to be able to view their own medical file if they wished. In practice, most did not ask for this, or they did not feel the need (76\%). From the $24 \%$ that wanted to view its own data, three quarters got access (18\%) and a quarter did not (6\%).

Of the patients who were treated by more than one specialist (Importance sample $n=177$ ), $100 \%$ felt it important that specialists kept each other well-informed. However patients experienced this fully in only $55 \%$ of cases (Experience $n=430$ ) between specialists, in $28 \%$ to some extent and not at all in $17 \%$. Nearly all patients (98\%) wanted the information different specialists provided not to contradict. In practice, $19 \%$ of the patients reports having received contradictory information.

Nearly all patients (97\%) thought it important to receive sufficient information upon discharge from the hospital, but only $84 \%$ received sufficient information.

\subsubsection{Information on coming home after having been admitted in hospital}

Many patients (98\%) stated that they would like to be in contact with the GP after hospital discharge, though in hindsight a large portion of them claimed the contact was unnecessary (40\%). Most patients (75\%) preferred the GP to initiate this contact. In a third of the cases, the GP did so (30\%).

\section{Discussion and conclusion}

\subsection{Discussion}

\subsubsection{Choosing specialist care}

Many patients want advice from the GP regarding decisions about referral and a quarter even want the GP to decide for them. This is especially true for older people, lower educated people and patients who have a low score on the Stable scale [16]. Actual experience shows that the GP makes the decision for a higher percentage of patients (33\%). This may be due to the fact that emergency patients who are being referred may not have the time nor capacity to make their own decisions.

The majority of patients, particularly older patients, prefer either a hospital nearby or wish to choose based on personal experience or the experience of relatives or friends. In practice, patients with cancer in particular chose a hospital nearby.

Patients with a curable condition and patients aged between 25 and 65 who are highly educated and have a high score on the Stable scale, more often wish to use information from newspapers or the internet to make a decision.

\subsubsection{Information on illness or treatment}

There is an obvious difference in the amount of information that different people desire [17]. Young people, older people, and those scoring low on the Stable scale, frequently only desire practical information. This finding is consistent with the findings from our earlier, qualitative study that too much information makes certain patients anxious. Possibly, it is these groups who wish to receive advice from the GP. However, there are more patients needing advice from the GP than there are patients actually receiving it Pharmacists could improve their position as information source as well. This is especially true for chronically ill patients, who regularly visit the pharmacy for repeat prescriptions.

Older patients and lower educated people use the internet significantly less as a source of information. The hypothesis that older people use the internet as much as other age groups, even when helped by others, is proven to be false.

Over half of the patients think the mutual information exchange between specialists is inadequate, and $19 \%$ of the patients indicated having received contradictory information. Possibly, more attention should be given to mutual collaboration between specialists.

Patients wish to receive more information upon discharge after having been admitted to hospital [18]. This seems most evident in patients suffering from a curable condition $[19,20]$, though this last finding could not be confirmed in this study.

Patients think the contact with the GP after hospital discharge leaves room for improvement, though in hindsight many patients indicated contact had not been necessary. It might be preferable then, for the GP and patient to arrange the type and frequency of post-referral contact upon referral.

\subsubsection{Strengths and weaknesses}

Strength of this study is that it has documented what information needs patients have, as well as what they actually experienced. Except for an overrepresentation of older people, the research population is similar to the non-respondents. The educational level of the respondents is similar to that of the Dutch population. The questionnaire was given out by GP practices. We do not think this has led to bias, as patients often used the questionnaire to express both their satisfaction as well as their dissatisfaction with the GP or specialist.

Only clear diagnoses, filled out by the patients themselves, were processed. This is why the MUPS group is small and the Other group is large. 
The Stressed subscale does not discriminate for preferences or experiences. Further research will have to show which concept this scale is based on. The Stable scale is discriminatory in various areas. This subscale also needs further analysis for validation.

\subsection{Conclusion}

The hypothesis from our qualitative research, that patients' desire for information on their illness greatly differs, is confirmed by the findings of the present study. Care providers should take these differences into account, and be sure to provide personalized information.

The hypothesis that the GP is very important as an adviser for referral was also confirmed. It is therefore highly important to inform these professionals on the characteristics of hospitals [21]. When undertaking an advisory role, the GP should be able to distinguish their personal opinions from objective information $[22,23]$.

Patients with a curable condition more often wish to use information from newspapers or the internet in making decisions. This finding is consistent with user research from websites with information on performances (Dutch Consumer's Organization). These show that people most often search for information on elective surgery, such as on the hip and knee, and cataract and cosmetic operations. Such procedures are usually single interventions that do not involve specific after care, and therefore resemble a product that a consumer can choose based on information regarding a provider's merits. The care provided for most other health problems does not resemble products in this respect: the outcome is more critical for the individual than buying other products, so there is more anxiety to get it right. This could explain why patients find it difficult to make these decisions on their own.

Only few people suffering from a curable condition wish to choose based on public information. These consciously deciding people are usually adult patients who are higher educated and stable. Health care policy makers (politicians, health care insurers, health care providers and researchers) seem to fit this profile. The danger in this, is that developments might be advocated that are based on what policy makers would want for themselves if they were a patient.

Only a limited number of patients uses published performance data on a limited number of health problems. In further developing and presenting these data, this should be taken into account.

\subsection{Practice implications}

The hypothesis from our qualitative research, that patients' desire for information on their illness greatly differs, is confirmed by the findings of the present study. Care providers should take these differences into account.

\section{Conflict of interest statement}

The authors declare that they have no competing interests.

\section{Acknowledgements}

We would like to thank all the patients who participated in the test phase and the definitive study. As well, we would like to thank Wim Benneker, for aiding in formulating the questions, the key figures of various organizations who judged the questionnaires, the GPs and their assistants who were willing to invite their patients, the staff members of the registration networks of Groningen and Leiden and the secretarial staff in Groningen and Leiden, who helped sending out all the questionnaires.

This study has been funded by ZonMw, Innovatiefonds zorgverzekeraars and Menzis, the Netherlands.

\section{References}

[1] Cleary PD, EdgmanLevitan S. Health care quality-incorporating consumer perspectives. J Am Med Assoc 1997;278:1608-12.

[2] Richards T. Patients' priorities-need to be assessed properly and taken into account. Brit Med J 1999;318:277.

[3] Marshall MN, Shekelle PG, Leatherman S, Brook RH. The public release of performance data: what do we expect to gain? A review of the evidence. J Am Med Assoc 2000;283:1866-74.

[4] Schneider EC, Epstein AM. Use of public performance reports: a survey of patients undergoing cardiac surgery. J Am Med Assoc 1998;279:1638-42.

[5] Hibbard JH, Stockard J, Tusler M. Hospital performance reports: impact on quality, market share, and reputation. Health Affair (Millwood) 2005;24:1150-60.

[6] Baker DW, Einstadter D, Thomas C, Husak S, Gordon NH, Cebul RD. The effect of publicly reporting hospital performance on market share and risk-adjusted mortality at high-mortality hospitals. Med Care 2003;41:729-40.

[7] Hibbard JH, Stockard J, Tusler M. It isn't just about choice: the potential of a public performance report to affect the public image of hospitals. Med Care Res Rev 2005;62:358-71.

[8] Berwick DM, James B, Coye MJ. Connections between quality measurement and improvement. Med Care 2003;41:130-8.

[9] National Centre for Social Research. British Social Attitudes Survey, 2006. Colchester: UK Data Archive; 2008.

[10] Berendsen AJ, de Jong GM, Meyboom-de Jong B, Dekker JH, Schuling J. Transition of care: experiences and preferences of patients across the primary/secondary interface-a qualitative study. BMC Health Serv Res 2009;9:62.

[11] Stubbe JH, Gelsema T, Delnoij DM. The Consumer Quality Index Hip Knee Questionnaire measuring patients' experiences with quality of care after a total hip or knee arthroplasty. BMC Health Serv Res 2007;7:60.

[12] Stubbe JH, Brouwer W, Delnoij DM. Patients' experiences with quality of hospital care: the Consumer Quality Index Cataract Questionnaire. BMC Ophthalmol 2007;7:14.

[13] Dillman DA. Mail and telephone surveys: the total design method. New York: Wiley \& Sons; 1978.

[14] Nunnally JC. Psychometric theory. New York: McGraw-Hill; 1967.

[15] Streiner DL, Norman GR. Health Measurements Scales. A practical guide to their development and use. Oxford: Oxford University Press; 2003.

[16] Schwartz LM, Woloshin S, Birkmeyer JD. How do elderly patients decide where to go for major surgery? Telephone interview survey. Brit Med J 2005;331:821.

[17] Maibach EW, Weber D, Massett H, Hancock GR, Price S. Understanding consumers' health information preferences: development and validation of a brief screening instrument. J Health Commun 2006;11:717-36.

[18] Sofaer S, Firminger K. Patient perceptions of the quality of health services. Annu Rev Publ Health 2005;26:513-59.

[19] Suhonen R, Leino-Kilpi H. Adult surgical patients and the information provided to them by nurses: a literature review. Patient Educ Couns 2006;61:5-15.

[20] Lithner M, Zilling T. Pre- and postoperative information needs. Patient Educ Couns 2000;40:29-37.

[21] Magee H, Davis LJ, Coulter A. Public views on healthcare performance indicators and patient choice. J Roy Soc Med 2003;96:338-42.

[22] Silvia KA, Ozanne EM, Sepucha KR. Implementing breast cancer decision aids in community sites: barriers and resources. Health Expect 2008;11:46-53.

[23] Entwistle V. Offering choices. Health Expect 2008;11:1-2. 